\title{
What comes out of Pandora's box?
}

\author{
Dirk Van Raemdonck, MD, PhD
}

See related article on pages 103-9.

In classical Greek mythology, Pandora was the first woman on Mother Earth, created by Hephaestus with water and earth. When Prometheus stole fire from heaven, Zeus took vengeance by presenting Pandora to Prometheus' brother Epimetheus. Pandora was given a wedding gift of a beautiful jar, with instructions to not open it under any circumstance. Impelled by her curiosity, Pandora opened the box and all evil contained therein escaped and spread over the earth.

Likewise, opening the mediastinum may reveal a variety of benign and malignant tumors whereby the ability to completely resect mediastinal malignancies may have a strong prognostic impact on survival in these patients. Tumors of thymus account for approximately $20 \%$ of all mediastinal masses and for nearly $50 \%$ of all tumors in the anterior mediastinum. ${ }^{2}$ Thymic malignancies comprise both thymomas and thymic carcinomas, including primary thymic neuroendocrine tumors (TNETs). ${ }^{3}$ TNETs are extremely rare tumors, accounting for only $2 \%$ to $5 \%$ of all thymic malignancies. Relative to carcinoid tumors in other organs, such as the liver and lungs, TNETs are extremely infrequent $(0.4 \%)$. Patients with TNETs, however, have a worse prognosis because of the more aggressive biologic behavior of the tumor, with more distant metastases and higher recurrence rates than their counterparts in other sites. TNETs can be further subdivided into well-differentiated neuroendocrine carcinomas (typical and atypical carcinoid) and poorly differentiated neuroendocrine carcinomas (small cell carcinoma and large cell neuroendocrine carcinoma). ${ }^{4}$ Because of the rare nature of these neoplasms, published studies are limited to case reports or small case series, with the largest until now, published in 2001, including 80 patients. ${ }^{5}$ As a result of the low incidence of TNETs, our knowledge on prognostic factors determining outcome is limited, and the best

From the Department of Thoracic Surgery, University Hospitals Leuven, Leuven, Belgium.

Disclosures: Dr Van Raemdonck is a past president of the European Society of Thoracic Surgeons and has contributed cases to the ESTS and ITMIG thymic databases.

Received for publication Nov 1, 2014; accepted for publication Nov 3, 2014.

Address for reprints: Dirk Van Raemdonck, MD, PhD, Department of Thoracic Surgery, University Hospital Gasthuisberg, Herestraat 49, B-3000 Leuven, Belgium (E-mail: dirk.vanraemdonck@uzleuven.be).

J Thorac Cardiovasc Surg 2015;149:110-1

$0022-5223 / \$ 36.00$

Copyright (c) 2015 by The American Association for Thoracic Surgery

http://dx.doi.org/10.1016/j.jtcvs.2014.11.001 treatment for these tumors is guided by these small clinical series in the absence of prospective clinical trials.

The article in this issue of the Journal by Filosso and coworkers $^{6}$ represents the largest series of TNET cases to date, including 205 patients. Data were pooled from 70 institutions from Europe, Asia, and North America that contributed to the databases of 2 international societies: the International Thymic Malignancy Interest Group (ITMIG) and the European Society of Thoracic Surgeons (ESTS). In total, 205 patients who were treated for TNETs between 1984 and 2012 were identified. So, during a period of 29 years, only 7.1 new cases per year on average were reported to these databases! The median overall survival of these patients was 7.5 years, with a 5-year survival of $68 \%$. The cumulative incidence of recurrence was $39 \%$ at 5 years, much higher than reported in recent series from the ESTS database for all thymic malignancies $(8 \%)^{7}$ and for all thymic carcinomas $(28 \%),{ }^{8}$ thereby confirming the aggressive biologic behavior of TNETs. Not surprisingly, overall survival was largely influenced by the Masaoka-Koga staging system $(P=.02)$, with better median survival for early stages (13.5 years for stages I-II vs $7.3,3.8$, and 4.2 years for stages III, IVA, and IVB, respectively), and by completeness of resection (hazard ratio, $0.343 ; 95 \%$ confidence interval, 0.119-0.992; $P=.048)$. Histologic subtype, however, did not have any significant effect on survival in this study $(P=.19)$.

This report represents the largest clinical series on TNET ever described. Nevertheless, the study suffers largely from its retrospective design, with data collected from many institutions over a long period into different databases from 2 international scientific societies. Data on the surgical approach (sternotomy vs others) and on the resection status (R0 vs R1 and R2) were available for only $64 \%$ and $47 \%$ of the patients entered into the database, respectively. Moreover, information on the histologic subtype of TNET, survival, and tumor recurrence was missing for $13 \%, 24 \%$, and $54 \%$ of the cases. In addition, no information on endocrine-related disorders was available in either database. Reported figures on overall survival and on cumulative incidence of recurrence, as well as prognostic factors identified in the study of Filosso and coworkers, ${ }^{6}$ may therefore be largely influenced by the amount of missing information. The study results should thus be interpreted with some caution. Nevertheless, Filosso and coworkers ${ }^{6}$ are to be congratulated for the enormous effort needed to collect and to analyze the largest series on TNET to date. This article provides the greatest evidence on the treatment of TNET available in the literature so far. It will largely help the 
thoracic community to better understand the specific behavior of these rare tumors. Further international collaboration between both societies (ITMIG and ESTS) to set up a prospective database is needed if we want to improve the quality of our data and our knowledge about these rare tumors. Only then we will be better prepared for what can be found in Pandora's box and what clinical consequences the finding of TNET may have for the treatment and follow-up of our patients.

\section{References}

1. Wikipedia. Pandora's box. San Francisco: Wikimedia Foundation. Available at: http://en.wikipedia.org/w/index.php?title=Pandora\%27s_box\&oldid=633703661. Accessed November 1, 2014.

2. Wright CD, Mathisen DJ. Mediastinal tumors: diagnosis and treatment. World J Surg. 2001;25:204-9.
3. Detterbeck FC, Parsons AM. Thymic tumors. Ann Thorac Surg. 2004;77:1860-9

4. Lausi PO, Refai M, Filosso PL, Ruffini E, Oliaro A, Guerrera F, et al. Thymic neuroendocrine tumors. Thorac Surg Clin. 2014;24:327-32.

5. Moran CA, Suster S. Neuroendocrine carcinomas (carcinoid tumor) of the thymus. A clinicopathologic analysis of 80 cases. Am J Clin Pathol. 2000; 114:100-10.

6. Filosso PL, Yao X, Ahmad U, Zhan Y, Huang J, Ruffini E, et al. Outcome of primary neuroendocrine tumors of the thymus: a joint analysis of the International Thymic Malignancy Interest Group and the European Society of Thoracic Surgeons databases. J Thorac Cardiovasc Surg. 2015;149:103-9.

7. Ruffini E, Detterbeck F, Van Raemdonck D, Rocco G, Thomas P, Weder W, et al; European Association of Thoracic Surgeons (ESTS) Thymic Working Group. Tumors of the thymus: a cohort study of prognostic factors from the European Society of Thoracic Surgeons Database. Eur J Cardiothorac Surg. 2014;46:361-8

8. Ruffini E, Detterbeck F, Van Raemdonck D, Rocco G, Thomas P, Weder W, et al European Society of Thoracic Surgeons Thymic Working Group. Thymic carcinoma: a cohort study from the European Society of Thoracic Surgeons database, J Thorac Oncol. 2014:9:541-8. 